\title{
Introduction to Cultural (Im)mobilities and the Virocene
}

\section{MOBILITIES AND NEW HYPEROBJECTIVITY}

The day the virus that came to be known as 'COVID-19' was identified in Wuhan, China, will be remembered as the beginning of the time in which everything stopped moving physically. The event's mundane announcement stands in stark contrast to the chaos its uncontrolled global spread would cause. This sounds like a straightforward story of causality and intention or direction of movement, but it is not. COVID-19's potency manifested in the realm of becoming: as an endlessly reported event, it did not change the Euclidean principles of spatial arrangement per se but challenged the world's axiomatic taken-for-granted-ness as a materiality within which we, as its sentient subjects perceive what is real and act on this perception. By becoming the new self-governing principle of various forms of movement, including travel, trade, leisure, labour, technology and more, COVID-19 transformed into an ontological magnet. The virus's by-proxy becomingness, its ability to change how movement happens or not at all, assumed various forms: because of lockdown policies, it ground automobilities to a halt; because of its accelerating infectiousness, it moved work to home; because of social distancing, it increased the use of the internet, filtering most socialisation through new media.

The list of changes can grow, but for students of socially and politically directed movement, or mobility, the key point is that, what used to be accepted as a norm in the study of material transformations changed (Adey, 2017, pp.6-7), also prompting alterations pertaining to the experience of late liquid modernity (Bauman, 2000). I take an extra step to argue that the core of the transformation is connected to the ways we are taught by experts to approach social changes in a scientifically sound manner, which unfortunately, is not interest free (Fuller, 1993, 2000). I will reflect in more detail on whether the changes will be permanent later in this study. Central to my thesis is to examine what Urry (2000, pp.2-4) proclaimed in his mobilities manifesto at the turn of the twenty-first century as a shift from reconstructing the social as 'society' to the social as 'mobility'. My questions are thus: what counts as a perception of the social as mobility in a recurring pandemic? Who defines 
such purposeful movements? When examining the COVID-19 context, we cannot talk about the entanglement of geographic movements in socio-cultural transformations the way we used to (Cresswell, 2006; Cresswell, 2010, p.21). Indeed, the geographic seems to have been subsumed in social interaction by the virtual, revising earlier studies of stillness in hypermobile contexts as a conception of 'aberration', or a 'failure of self-management' (Bissell and Fuller, 2011, p.7). If anything, the moment our lives stood still, regional, national and international centres of governance used our physical immobility to tighten control over us and solidify their power to make decisions over life and death. To some extent, and despite the presence of free-flowing discourses in global fields, the governance of mobility per se can be a beneficial technology, but, as the American example of the Trump administration attests, in the hands of inconsiderate and ruthless legislators it becomes a deadly weapon. In addition, by seeing their 'right' or 'option' to migrate or travel diminish or be even more controlled, many people lost the opportunity to physically remove themselves from unpleasant or dangerous contexts (Vannini, 2011; Cresswell, 2013; Sheller, 2018; Bianchi et al., 2020).

Curtailing some mobility liberties in COVID-19 contexts that featured in earlier studies of mobility either as research novelties (Crang, 2001; Cohen, 2005) or as social, cultural, and political givens (Bissell, 2014; Bissell and Overend, 2015) changes the rules of what constitutes an agreed reality by which citizens abide and which they share. The realisation suggests a return to definitions of 'crisis' - more specifically how it is managed and what sort of futures new styles of management draft for humanity and our planet. To revise Urry, far from removing the 'social' from conceptions of society, the viral crisis merged it into discourses of the right to movement: as a form of leisure; an escape from persecution or death; an opportunity to improve one's social status; or the basic right to be with loved ones, physically and emotionally. Scholars such as Higgins-Desbiolles (2020a, pp.3-4) read this undoing as the destruction of the scaffolding on which neoliberalism has stood so far, a point of which I am uncertain. However, before I explore such arguments, I will bifurcate my definition of 'crisis', by stressing that every change can both obstruct beneficial opportunities and forge the promise for new ones. Feminist scholars (Levitas, 2013b; Büscher, 2020) suggest that to back away from the edge of extinction, humanity needs another great transformation that will neutralise the negative effects of the one in which we live today, as Polanyi (1944) outlined decades ago (Tzanelli, 2015). We just need to know how to detect the latter and, as researchers, identify who can realistically access them. 


\section{EPISTEMOLOGICAL AND METHODOLOGICAL CONSIDERATIONS}

In established repertoires of social scientific critique, knowing how and where to look for answers forms the methodological basis of realist accounts of the social. However, there are variations even within realism, ranging from crypto-positivist and critical to more experimental, which pluralise the 'real', and thus do not accept its monadic presence in the world. Indeed, for a fulsome analysis of any 'crisis' we may have to look past traditional analyses of control, which do not acknowledge the symbolic dimensions of the ways events or clusters of events are recognised as an all-consuming social reality (Hart, 1993). In line with this statement, I clarify that this book is not intended as a study of political macro-mobilities, even though Part I deals precisely with the globalised and globalising dimensions of what I call 'the Virocene' through the study of the recent global pandemic. Rather, I wish to connect grand mobilities to the psychic and affective micro-movements that such crises induce, as well as the ways they affect established patterns of everyday movement and sociality.

Methodologically, my approach will consider such experimental theses as Nelson Goodman's (1978) original 'worldmaking' account of coexisting world (or reality) versions, but also artistic movements, such as 'magical realism' and the 'new objectivity', in which reality assumes amplified dimensions without necessarily losing its unity (Tzanelli, 2020a: Preface and Introduction). A multimodal collection of audio-visual and textual resources from new social media sites, such as YouTube, international TV channels, blogs and the international press, as well as documents released by international policy coordinators (e.g., WHO or the UN) is enacted to analyse these (Kress and van Leeuwen, 2001). Mixed methods are necessary, when one data source is inadequate, the explanatory framework needs expanding, or the adopted theoretical perspective requires more elaboration (Greene, 2007, p.20; Cresswell, 2015). The introduction of complexity in our socio-cultural life due to overlapping crises renders combined methods and multimodality useful tools. Such methods draw on pragmatism and critical realism to question binaries between qualitative and quantitative, truth and untruth, positivism and constructivism (Felizer, 2010). Hence, my intention is far from crafting a dystopian story about the status of reality in the days of the coronavirus pandemic (as indeed, I have done elsewhere - see Tzanelli, 2020b). As my analytical account progresses, any optimistic pluralism will give way to uniform accounts of perception in specific realms. This uniformity colludes with forms of action on people's lives that cannot be easily disputed as untrue and unreal, when they are subjected to tests (Boltanski and Thévenot, 2006). In some instances, this 
uniformity is challenged in virtual domains, which may be holding the key to more sustainable futures of travel and tourism, but also healthy resuscitations of topographically defined 'community' and individual psychic integrity. My conclusion on exactly what constitutes a 'crisis' as a category will not be pluralist, but pragmatic in a phenomenalist fashion that accommodates the idea of accepting pluriworlds.

At times, my analytical convergences will tread a fine line between fiction and reality, because of their hypothetical magic. This comes close to David Beer's (2014) understanding of punk sociology, seemingly cancelling the classical music notes Ruth Levitas introduces in my analysis. Although, as will become evident towards the end of the book, I remain more than sympathetic to Beer's thesis, I am also apprehensive about the audiences he wants to have and their priorities. Unlike both Beer and Levitas, I emphasise that solutions are process-driven, hence poetic, associate such poesis neither with art nor with science. My thesis focuses on notions of exploration as a form of creativity shared by humans in varied degrees. I will develop a thesis around the concept of the 'Virocene', which is as iconoclastic as Beer's (2014, p.38) call to be punk and as conventionally utopian as Levitas' (2013a, p.221) belief that solutions are found in the capacity of human nature to hope even in the face of unavoidable catastrophe. The putative dialogue with these two scholars is passed through my own experimental sieve, which is based on performance theory that removes science fiction from its artistic context and places it in policy fields. In fact, my science fiction vocabulary helped me in the initial stages of concept-building to also consider the unprecedented in less palatable futural scenarios that we tend to silence in favour of straightforward discourses of hope and recovery, both in material and figurative terms. Just so I am clear, my relocation of science fiction is not intended as an endorsement or performance of policymaking, only a method to dispel the benefits and follies of what Levitas debates as 'utopia as method'. Hence, this study is a meta-commentary on such discourses, which should not be confused with that of literary, cinematic or journalistic discourse.

Levitas (2013b) used conceptualisations of utopia to excavate the ways institutions come to produce realities. Through them, she suggests a way to synthesise a view of the future. She uses these scenarios to interrogate the ontological status of humanity and proceeds to reconstitute the social in a critical manner. My objection to this method is Levitas' assumption that scenarios are produced by institutions: in what follows, I focus on free-flowing discourses in socio-cultural fields, which are adopted and adapted by institutions. This makes space for interrogations of the ways such discursive flows are perceived in everyday practices, including investigations into their popular cultural valences. My decision to adopt post-Marxist, anti-humanist tools is analytical in nature: the first thing the Virocene modifies in our lives is our 
relationship to material realms of being, but the deepest change is psychic and collective. This is central to my thesis and my conclusion on what severe virological crises of epochal dimensions in general do to humanity and its physical environs. Likewise, coupling humans with environs is purposive and post-human: it is conducive to the realisation that as the primary agents (rather than actants) on earth, we exert power over non-human ecologies and systems with great arrogance. I believe that human agency stands at the top of the hierarchical chain of action and cognition, asserting our planetary tyranny.

Levitas focuses on Bloch's uses of music's utopian surplus to articulate the 'not yet': 'what goes much further than anything so far known' (Bloch cited in Levitas 2013a: p.222). She identifies the ontogenetic power of musical articulation in the hermeneutics of emotions, which can artistically connect the light of music to the darkness of death (ibid., p.223). The darkness of the lived moment, the inability to grasp our immediate situation because we are immersed in it, is supposed to 'unabstract' categories of music. However, Levitas does not really elaborate on categories of musical articulation and what they do to our conceptualisation of a situation: importantly, excluding some of them produces or mostly asserts predispositions towards reality. There is an element of epistemological arrogance in this move even when we begin to debate positive future scenarios. In music we can account for a multiplicity of articulations, including tenuto (lengthy and/or louder play of a particular note), marcato (short-noted but full-length, louder, and forcefully played notes dominating the environ), staccato (shortened and detached duration notes), and legato (connected by smoothly played notes). All four styles correspond to methodological motifs in my study, and, I would add, any study of social and cultural phenomena. By varying articulation between the third - Beethoven's musical motif - and fourth styles, one allows for better musical development of life. By muting some keys (e.g., turning them into barely audible staccato), some aspects of musical development are obstructed.

I think that excessive optimism can do more damage than allowing some room for contemplating disaster, without turning it into a sport. This method shares with Berlant's (2011, pp.14-15) thesis on 'cruel optimism' the basic Delezean premise that fantasy affects not individual nervous systems but the collective-social one, at the most basic level to structure feeling rules. What it does not share is the rejection of the heuristic usefulness of radical singularity (i.e., talk about globalisation, climate change, pandemics, neoliberalism or capitalism in abstracto) in our analysis of perception and (non-)action (ibid., pp.15-16). Excessively muted staccato even in ethnographically informed contexts, can endorse the violence of abstraction (Comaroff and Comaroff, 1999), but an overemphasis on particularity ignores how individual and collective intuitions of crisis always stem and associate with the massive and the unprecedented challenges that societies face. There is no doubt that sustaining 
a hopeful stance in the face of adversity helps with morale and possibly allows more room for play and experimentation (on art performance and utopia see Büscher, 2020). However, it may also mute the forms of pluralism to which we may not actively subscribe or do not cover in our research (ibid., p.59). Again, to clarify, alternative or adversarial arguments need not make their way into a thesis and mar its coherence to be acknowledged as different. The issue can extend beyond research focus: the likelihood of 'hearing without listening' is often amplified in artificial environments, argues Barenboim (2008, p.37), providing that music styles are not metaphors but extensions of social methodology and real social inequality (Back, 2007). Ironically, some hopeful discourses fly in the face of COVID-19 as a biomedical reality: world experts warn that the idea of full recovery from COVID-19, even in mild cases, is not always possible, with many people sliding into chronic health problems after infection (Harvard Health Letter, 2021). Voices from WHO also suggest that COVID-19 may not be the biggest misfortune humanity will face. The chair of the WHO's strategic and technical advisory group for infectious hazards, Professor David Heymann, argued in late December 2020 that "the "destiny" of the virus is to become endemic, even as vaccines begin to be rolled out in the US and UK' (Davey, 29 December 2020).

Although the social and the physical domains should not be conflated, we see such blends taking hold in authoritarian versions of mobility governance, including both populist (Scribano et al., 2019) and market variations (Bærenholdt, 2013). In this instance, articulation becomes an extension of policy, as this features in the actions and inactions of technologies of listening (Urry, 2016) and not music as a form of art. The wave of hopeful policy discourses that hit the news after the roll-out of several vaccines around the world can also be considered as part of governance strategies: UK Prime Minister Boris Johnson's boasting about the UK being the first country to administer the Pfizer vaccine and further arrange for the use of AstraZeneca and other vaccines faster than anyone else (see also Matthews et al., 8 January 2021) is, in the context of Britain's global post-Brexit isolation, rife with nationalist overtones. Whilst I subscribe to the idea of hopeful futures, free of viral obstructions, which can allow the world to flourish en mobile, realism suggests caution - a 'what if' respecting more the messenger we tend to shoot before getting to know, because they carry unpleasant but accurate news. We must learn to assess such possibilities with the openness that we may or may not find in policymaking. The 'Virocene' of this study assumes epochal proportions, which extend beyond COVID-19 as one particular virus (we live in an era of infectious diseases that are partly of our own making, whether we like it or not) or as a physical viral reality (COVID-19 is by now a style of stillness and mobility, unevenly distributed across global populations, therefore a mode of governance). In fact, the Virocene is more generally about the infectious nature 
of crises, and this would include climate change, capitalist malfunctions, racist and gender violence and more. The nature is human and steeped in phylogenetic norms of temporal significance: the modern Greek word for virus is iós. The origins of the word points to two correlated Indo-European variables: the proto-Hellenic *ihwós derives from the proto-Indo-European $*(\mathrm{H})$ isu-, which refers to the arrow, and *wisós, which refers to fluidity, slime, or poison, with a suggestive connection to Sanskrit वषि (víșa), from which we have the Latin vīrus. The Virocene is about the plague induced by uncontrolled bordering and mobility, not as an allegory but a natural mapped extension of reality. Hypermobility removes stability from self-perception at individual and collective levels, thus leading to a crisis in self-presentation. If we limit my thesis' analytical validity to a 'metaphor' or an 'allegory', then we miss its psychic, imaginary and atmospheric dimensions which I discuss below.

As opportunities for goal-directed movement diminished or altered, so did our right to always keep all possible options open to move. The onset or amplification of virtual engagement caught some societies unprepared, because of differential access to resources on a global scale (Ballantyne, 2014; Carmody et al., 2020; Tzanelli, 2021b). Generally, the Virocene expanded the representational and simulatory regimes on which societies organise perception. Here it becomes obvious how I disagree with Berlant. I will discuss the amplification of such regimes as part and parcel the 'New Hyperobjectivity': the reorganisation of reality in everyday life and organisational and institutional contexts as a response to the viral crisis. Where the concept of the Virocene will help me to examine the material transformations induced by the prevalence of infectious contexts, the New Hyperobjectivity will help me to assess the experiential and emotional aspects of these transformations in terms of directionality, from the massive to the miniscule. Hence, I will treat the micro and macro-contexts of (im-)mobility as parts of a mega-system of perception, which informs the management of human and natural spheres. Instead of vilifying technology or treating it only with suspicion, as Levitas (2013a) does, I prioritise its methodological usefulness. To trace our location, Ahas (2011, pp.184-186) argues, we need to consider the role of devices (mobile phones) in what he calls the 'active' and 'passive' positioning of movement. The observation is pertinent both as a metaphor and a reality of mobility in the context of the pandemic: passive positioning 'uses a mobile operator's memory files, that is location data automatically stored in memory or log files', so there is less agency involved in positioning the owners of technology; active positioning is enabled through consented mobile tracking to make the user's life easier (ibid., p.186). We deal with a bifurcated vision of perception and action, whereby either we are subjected to an Orwellian dystopia, or technological manipulation of data makes us safer and more mobile. In both cases, positioning draws on memory 
files, for which we are billed but which we own; both cases are extensions of the Greek ihwós, which aims at, directs and can potentially infect.

Archives become identified with dominant historical narrations of key world events. Roitman, who nicely documents how changing the pessimistic arc of a narrative can propel humans to radical and positive action, tells us that a crisis itself is mobilised as a means to access historical truth, and even a way of thinking of history itself (Roitman, 2013, p.3). To exemplify this, she points to Luther King's last-minute changes in his planned speech entitled 'Normalcy-Never Again', for his Lincoln Memorial Speech of 28 August 1963, to accommodate a scenario of hope, which was missing from the original speech (Roitman, 2013, p.1). I intend to follow a similar arc for reasons exceeding rhetorical refinement and affective impact. I will consider Orwellian dystopias of surveillance in relation to the formation of historical records before and after the global spread of COVID-19. In the following part I explain that the 'Virocenic archive' stores our geographical movements, and the act of storing generates opportunities for reciprocal inspections: of our movements, our government's actions, the changes viral immobilities impose on the environment, and so forth. The more we store, the more we become overwhelmed by data, says Beer (2018), and the more polities become vulnerable to collective emotional surges supporting institutional incrimination. This is how the physical virus produces its affective extensions à la Berlant as an ihwós.

The COVID-19 pandemic assumes the proportions of something bigger than a particular spatio-temporal happenstance also because it develops into an atmospheric understanding of who we are in the world. Partly in agreement with non-representational theorists, such as Thrift (2008), Elias (1992) criticised much earlier than them the dichotomy between physical and social environments. With particular interest in temporal configurations, Elias (1992, p.30) pointed that such tendencies introduced irreparable divisions between objective and subjective temporalities, which fed into and were fed by a schism between epistemological objectivism and philosophical subjectivism. This split is examined here as a manipulation of realities, not a given. It has immense consequences for the ways we study phenomena such as pandemics and other alleged human-made crises and should prompt us to be cautious toward 'big data'-driven explananda that both scientists and sociologists derive from the compilation of statistics and growth/decline charts. Such a social scientific approach would give way to a colonisation of human comprehension, leading to an eradication of experience from crisis archives (Beer, 2018).

Because they mediate between the human subjective experience of material objects and events that never speak directly to other human subjects, 'atmospheres' may not be graspable in a conventional sense. Atmospheric understanding is always partial, if we follow Morton (2013, p.15): like 'hyper- 
objects', big atmospheres of the unknown are 'not just mental constructs but real identities whose primordial reality is withdrawn from humans' - otherwise put, they are objects in general that embrace big realities with aesthetic and ethical properties. Much like climate change, COVID-19 is an objectified situation that stands apart and beyond things we can fully grasp when it accumulates in clusters of events, consequences but also scientific explanations and experiments. Assuming the proportions of a cosmic phenomenon that brings upon disaster, the Virocenic hyperobject acquires the properties of a moving evil (dys: bad -astron: star) taking place against a previously more stable background. When we praise mobilities to the future, we would better be careful what we wish for.

Studying the structures of meaning-making that humans and their collectives employ to understand hyperobjects invites a return to Karl Mannheim's (1952) notion of 'units of sense'. Intriguingly, this has recently found innovative applications in new media theory to elucidate that the intertwined nature of meaning-making is digitally transferable messages (La Rocca, 2020). Levitas (2013a, pp.238-239) also notes how technology can alter the musical ambience. My use of Mannheim's thesis is more extensive: it points towards the modes of mediation assigned to objects when we are struggling to make sense of the reality in which they participate and/or produce. Hyperobjects are understood by humans as both interior and exterior realities in what Mannheim refers to as their documentary sense. In this mode, we could constrict the 'Virocenic Hyperobjective' to human interpretations of material, infrastructural and legislative effects, prioritising what Arendt (1978) called the 'unprecedented', which needs documenting and storing for posterity. However, I will not follow this pathway.

Arendt's anthropocentric interpretation would reduce ecological analysis to politics and exclude the assessment of COVID-19's impact on physical environments. It is better to acknowledge that in COVID-19 contexts, such brutality acquired a split representational face, because the accelerated spread of the virus brought into focus pessimistic scenarios about the end of the world rather than humanity (Morton, 2013). This is an escalating and interactive natureculture, environment-human catastrophe, as well as an Arendtian imaginary of undoing political structures through retrogressive social movements of the alt-right (e.g., Scribano et al., 2019). Significantly, the same climate of insecurity inspired the revival of new utopias of post- or degrowth, green living, micro-social solidarity of the 'slow movement' type, and new visions of communitarian care (Kallis and March. 2015). I will return to anthropocentric tropes of disaster and material of human excess and self-destruction when I will discuss arguments addressing the effects of capitalism on health and the environment (Zuboff, 2019). It would not be injudicious to argue that COVID-19 has worked, so far, as a magnet for a variety of public and popular 
understandings of what may be understood as a 'crisis': an epidemiological Armageddon; a metaphor for infectious intrusions into a clearly demarcated 'body politic' by ethnic and social others (i.e., the working-classes, ethnic minorities, refugees and asylum seekers); a regard for 'hospitality' in terms of inside/outside, labour/consumer; in short, an inclination to review the grand scripts of late modernity that regard mobilities as a progressive development through binarisms.

Acknowledging or celebrating materiality does not necessarily solve problems, it just plants them in Paradise. There is a conspicuous to me contradiction in the styles adopted by mobilities scholars to explore such scripts, especially whenever they attempt to foster connections between human interiority and the outer world. In the new mobilities paradigm, which promises to respect the materiality of purposive movements, this often features as the negative image of the romantic movement, which turned emotions into a panacea. Without turning their back to phenomenology (I would say far from it), some mobilities scholars turn materiality into their epistemological priority, partly because it is easier to translate its effects into 'reality' and partly because having instead recourse to the spaces of the human psyche blocks testing: it is impossible to embody the human interior or prove that its movements and drives have measurable impacts on 'outer things' (Chrisholm, 1988). Mobilities scholars who work on atmospheres are particularly susceptible to such criticisms, so they often choose to reduce connections between the outside and the inside to metaphors of embodiment. Still, nevertheless, fewer of them venture into the emotional interior. Instead, they analyse atmospheres with a detachment from their emotional implications, often collapsing the interpretive gap between them and their early phases we know as 'affects'. As a result, affective occurrences become emotions, which are then fully integrated into the material landscapes and spaces they study: the emotional collapses into the rational world.

This observation relates to my main thesis on the Virocene as the atmospheric after-effect of what is perceived as a 'long temporal unity'. There is great potential to talk about such after-effects, where scholars have talked about 'stretching': Jensen (2021) introduces the notion of the extended body to debate the ways individual bodies become extensions of the environment and engage with the world. He also introduces the 'elastic situation' as another metaphor in his analysis of the effects of COVID-19 in everyday life to explore the meaning of 'social distancing'. However, emotions are totally absent from this otherwise astute analysis, which also draws on classical sociology (symbolic interactionism). Working on the edge of anti-humanist beginnings, while discussing how COVID-19 may teach us to value mobility more, Cresswell (2020) refers to Canguilhem's thesis on the body. He notes equally astutely that because the freedom to move between and across different forms of border makes us susceptible to infection, we have become accustomed to criminalising 
mobility, forming metaphorical continuities between pathological and moral tropes of bodily hygiene. Although there is truth in the observation, its merit does not exceed the moralising nature of that it seeks to contest. Significantly, neither scholar ventures into virtuality as a mode of 'actuality' to discuss the status of perceptions of mobility in contexts of restricted movement, and both display an interest in moral tropes. The absence of such discussions conforms with the paradigm's rooting in de-sublimating material processes - the opposite of what the Romantics advocated in their discussion of the uniqueness of human individuality, which is rooted in affective and emotional atmospheres. Following the 1960s avant-gardist revolutions, such Romanticism began to flicker as a social movement and eventually became the maiden of neoliberal 'pluralism' (Chiapello, 2004).

All in all, by oscillating between a staccato and legato, both scholars mute the emotional dimensions of magical creativity and thus a significant aspect of aesthetic worlds. In talking about 'de-sublimation', I introduce a persistent methodological key, the only tenuto in my study: if 'inner infinity' (Morton, 2013, pp.162-163) is inaccessible and mobilities scholars can only talk about atmospheres and events by introducing some material constancy in their studies, perception can be stabilised too. Digital analysis posits several problems for a mobilities scholar in recognising the value of 'actuality' in the perception of any situation, including that nominated as a 'crisis'. By 'actuality' I do not refer to physical manifestations of sociality or face-to-face engagement, nor do I resort to metaphors of embodied and/or moral hygiene, which political discourse uses to turn COVID-19 into a 'crisis'. That would amount to foundationalism. Instead, I refer to the ways our imagination gives birth to options that shape different world versions, each with its own potency and effects on reality. Unfortunately, because such options are spiritual occurrences that fail to become visible, scholars (and it would be inaccurate to exclude myself) start using material metaphors instead of analysing the failure itself. There is nothing wrong with this move per se, until the metaphor replaces the possibility to critically assess the presence of more than one materialities and idealities, and thus pragmatic options. This is also my reservation with classical debates on the imaginary constitution of society and the ways it fosters hope for viable or 'sustainable' futures.

I contend that these observations should be seen as part of the new mobilities paradigm's biographical trajectory from Lancaster's sociological laboratories to other parts of the world, and especially the Nordic European academies, in which it currently thrives. There is great ambiguity when it comes to the paradigm's positioning in sociological traditions, whereas geographical schools have embraced it freely and claimed it as their own territory (Sheller, 2017). This book endeavours to explain why this disciplinary move has been rather rushed. This is not a coup to 'claim' the paradigm for sociology instead, only 
to accentuate the muted keys in its synthesis: sometimes a tenuto should be introduced in staccato or legato constancies to identify motifs. The suggestion is crucial in this study because it helps us to identify the atmospheric coordinates of the real 'crisis' introduced by the Virocene: of a continuum between emotional distance and sensory distancing. The realm of the sensible accommodates both in various entanglements of perception and action, producing categories of human and nature as objects, rather than subjects/agents. The demotion of subjective agency to objectivised presence produces a world of objects guided by the menace of elimination. The Virocene proposes a social-scientific scenario whereby the earth is boarded by alien forms of life that colonise it (see for example Scribano, 2020b, p.15). The real dis-aster becomes the ways a virus takes over the sensible regime that organises all post-human entanglements on the planet.

One of the founders of the mobilities paradigm, John Urry (2007), repeatedly mobilised Marx in his dissemination of ideas, often blending them with philosophical and geographical analyses that drew on post-structuralism and post-modernism. Marx is no stranger to the atmospheric paradigm of movement and its affective-come-emotional extensions, as Anderson (2009) notes when he discusses the Marxist observations on revolution. The visceral dimensions of experience have been for Marx important, in contradistinction to what Judith Butler's (1993) earlier work purported with regards to the production of sex/gender matrices. Recently, Butler (2015) corrected this by resorting to explorations of social movements as assemblies of visceral action and affective embodiment. As Marion Young (2005) has noted, the 'lived' female embodiment is often characterised by tensions between transcendence and immanence, intentionality and discontinuity, thus producing the female body as an ambivalent site. To me, Young's observation is nothing short of a thesis on atmospheres, which has suffered emotional mutilation on the analytical table. Another sociological theorist from Lancaster sociology at the time of writing, Scott Lash (1994), noted a few years before the establishment of the Centre for Mobilities Research, the putative differences between modernist and post-modernist arcs: whereas the former has been criticised for a taken-for-granted utopian 'metanarrative of social change', the latter adopted a 'dystopic evolutionism we associate with the likes of Foucault' (Lash, 1994, p.112). We need to move to a 'third space', he argued (ibid., p.113), in which a 'fully different and more open-ended scenario' can unfold with the help of reflexivity. Taking itself as the object of reflection, modernisation can help us escape the destructive subjugation of lifeworlds as amalgams of our inner and outer natures. Lash's aesthetic mutes the emotional, but like Jensen's at least it gestures towards a structural Körper, an objectified being that 'stretches', 'extends' and 'moves'. 
It seems that the current discourse about mobilities and utopian futures bears echoes of this clash of arcs, mostly siding in policy with modernist manifestos, and at times silencing its disciplinary legacy in sociologies of reflexivity. When promoted to a persistent tenuto, reflexivity can be at war with the body not as a material site, but a putative domain: an emotion, an affect, or clusters of them. The alternative space began to be formed in some neovitalist discourses with a feminist arc supported by Mimi Sheller, another founding scholar in the new mobilities paradigm (Sheller, 2014b, 2014c), and has definitely been present in the work of Sarah Ahmed $(2004,2014)$ for a while. This trend asserts materiality while adequately acknowledging the Lieb or its feeling, sensing and emotional dimensions as experiences (Merleau-Ponty, 1962, p.136; Crossley, 1995, p.43; Shilling, 2012, pp.244-245). This trend fuses traditional sociologies with new schools of thought that pay attention to experience and systems at the same time (see also Tzanelli, 2015, 2016b, 2020a). In fact, many of the aforementioned debates could be connect to Bourdieu's conception of 'reflexive sociology' as the phenomenological production of human agents in a 'social topology' (Bourdieu and Wacquant, 1992, p.12). Without ignoring the 'spatial turn', I believe that scholars of this paradigm should not explore movement primarily as a variation of spatial configurations. The problem with the atmospheric portfolios in the new mobilities paradigm is that it has collapsed a much-needed zeitdiagnistische Sociologie to a Raumsgeist. This book attempts to fuse these two dynamics into a more coherent project of imaginaries of and about the future of humanity and our planet, by taking seriously in temporal-affective terms the dark clouds formed in a Virocenic horizon refusing to clear.

The 'social imaginary' has been studied extensively in the social sciences. The term, which is traced in the works of Castoriadis ([1975] 1987), Anderson (2006) and Taylor (2004), emphasises how the social comes to life when we establish associations between ideas, people, and objects. Such relations commence with personal imaginings and are meaning-making mechanisms: they produce a symbolic matrix within which we imagine our collective social worlds. In Castoriadis' thesis, the individual ('radical') imaginary, which asserts its autonomous creative capacity over the collective, feeds into the collective ('social'), which acts as a community-making mechanism. Useful though this differentiation is, it discards the possibility of pluralisation: for every social imaginary there may be many radical ones; in addition, the social imaginary itself may mutate across different domains. By the same token, we cannot think of 'imaginaries of crisis' as stable laboratory products: in a real environment, they communicate with other imaginaries and often become conflated. Many radical imaginaries can coexist with a dominant social one within a single lifeworld. If we 'mute' this, our staccato refuses to acknowledge that humanity consists of multiple worlds (or 'pluriworlds' - Escobar, 2018) and, 
correspondingly, our natural ecosystems are complex pluri-systems with very fragile ecologies in the Anthropocene (Braidotti, 2013; Tsing, 2015). At the same time, if we let the staccato of plurality overwhelm systemic organisation, we end up with an impossible patchwork universe. I therefore do not discard the significance or value of the socio-technical realm in imaginary formations of community, which, in its most trusted, if flawed form, is represented by nation-orientated scientific and technological projects (Jasanoff and Kim, 2009). Such imaginaries encode visions of what is attainable and possible in scientific-technological terms, but also the norms and mores governing life therefore, understandings of 'good' or 'evil' action (Jasanoff, 2015a).

The current COVID-19 crisis does not develop in a void but is enmeshed in a web of global crises that humanity and its natural habitats face, including wars, massive population movements, as well as climate change and viral outbreaks. This means that imaginary representations of society in regard to the crises are the product of a complexity that extends beyond a particular cluster of activities (say, tourism, or automobile circuits) or a system (Urry, 2003). As different systems collide or begin to interweave, new structures of life emerge that humans conceptualise always at the edge of chaos in multiple spatio-temporal planes (Urry, 2005b, p.3). Otherwise put, any 'crisis' comes to life when it is discussed as such, often in contexts of interwoven narratives that activate speculation on the flourishing or threat of life (Roitman, 2013). Levy and Spicer (2013, p.660) help us to focus analytically on assemblages of crises with their conception of 'climate imaginaries' as socio-economic systems structuring a field around shared understandings of the climate. They suggest that imaginaries become dominant only when they articulate popular interests and identities and align with economic and technological considerations pertaining to systems of mobility. Then, they conclude, imaginaries form 'value regimes' that are re-circulated in the social field to shape social action and policy. Mobilities of the kind with which I deal evolve around practice, power, and the production of meaning (Cresswell, 2006, pp.1-10). As meaning-making machines, Virocene imaginaries articulate both political interests and tropes of hope associated with anti-establishment perspectives.

We deal with new complexities that also redefine what the 'environment' stands for in fields of action and perception, and the extent to which it is valued either as 'nature' or a post-human assemblage, in which humans can flourish only if they respect it (Smith-Nonini, 2017). 'Complexity' is embedded in conceptions of sustainability, which disclose environmental, socio-cultural, and economic dynamics, each vying for domination over the rest, as each of them may be wedded to a different social philosophy and course of action. Where environmental sustainability calls for reducing resource consumption, socio-cultural sustainability focuses on community participation, respect for cultural difference and urban justice, and economic sustainability prioritises 
local/national economic growth and livelihood protection (Sneddon, 2000; Iaquinto, 2018). Methodologically, this invites scholars to side with critical epistemologies, which better acknowledge the crisis of representation that societies face today (Jennings, 2009; Denzin and Lincoln, 2011).

Latour (2005, p.79) explains that imaginaries need cognitive and textual 'images' to enable social agents to realise the social. In discussing methodological applications of the thesis on social and cultural imaginaries to mobilities studies, Couldry (2012, pp.27-28) points to the importance of studying meeting points and accumulations of resources and routines in new media sites, where such 'images' are stored. Mobilities of ideas and practices emerge in media-saturated contexts, where social imaginaries are shared, thus producing a collective symbolic matrix. Gaonkar and Povinelli (2003, p.386) argue that, today, societies which prioritise the circulation of ideas experience an intensification of 'mediated public forms'. Valaskivi and Sumiala (2014, p.233) remind us that widely distributed (digital and print) texts, images, and symbols both have a materiality that activates the circulation of imaginaries and participate in articulations of social action. These imaginaries of (un) sustainability can be place- or country-specific, as discourses reflecting global challenges to tourism tend to re-localise tourist activities. Because places are never finished products but subjected to processes of flow and mobility (Urry, 2007, pp.18-20; Cresswell, 2015, pp.116-117), I read such textual imaginaries at the intersection of the global and the local, stressing where and how they acquire more regional or national/cultural resonance.

On the putative domain of atmospheres, the dys-astrous is broadcast as a dystopian movie. Such dystopian scenarios have developed in popular cultural domains across two different cinematic sub-genres: one focuses on virological outbreaks and the other involves climate catastrophes (Fiskio, 2012). Known as 'cli-fi' in popular culture, such movies assume the worst for life on earth, proffering the possibility of total annihilation. These stories have been criticised by scholars and policymakers for unrestrained pessimism followed by lack of contributions to clear solutions to the problems humanity and the planet face (Whiteley et al., 2016). Both Urry (2016, pp.52-53) and Klein (2014, p.258) comment on the fatalistic arc of these films, which may lead to inaction and lack of planning of viable alternatives, allowing centres of power to intensify catastrophic geo-engineering. Although staging such scenarios in film for policymaking purposes conflates divisions between creative work and policy labour, in this book I highlight the points at which the two domains come in contact phenomenologically. It is not coincidental that in his exploration of dystopian presents of climate change, Urry (Urry, 2007, p.287; Urry, 2011) discussed the presence of warlordism in drought-inflicted regions on the African continent. We might as well have been watching the Mad Max saga (1979, followed by three films: Mad Max 2 (1981, released in the United 
States as The Road Warrior), Mad Max Beyond Thunderdome (1985) and Mad Max: Fury Road (2015)) or Annihilation (2018) on the big screen with such grammatological enunciations of an imminent dismantling of world orders.

The aesthetic realm begins to communicate in this unlikely popular cultural dialogue with the ethical and the political order of things, producing possibilities through the anticipation of the worst. This is in fact a contact zone facilitated by possibilities to amplify the real - what the new objectivity suggested in the domain of art. Jasanoff's (2015b) discussion of science fiction's role as a collection of visions that 'integrate futures of growing knowledge and technological mastery with normative assessments of what such futures could and should mean for present-day societies', is important. The 'Vi-fi genre' (my neologism for 'Virocenic fiction') provides a way to interrogate and even critique what I discuss in Part II as the 'Virocenic archive'. Focusing exclusively on practices of blaming and the survival of colonial violence can rigidify future prospects, leading to hostility towards technological and scientific achievement. It must be stressed that to suggest that art takes over scientific tasks is both naïve and dangerous - divisions of labour and expertise exist for a reason, and this involves tackling risks and crises efficiently.

Often, the press generates confusion by exaggerating contact zones between Vi-fi and health and safety policymaking: such is the case with a Guardian article, stating then UK Health Secretary, Matt Hancock's recent admission that Contagion (2011, dir. Steven Soderberg) haunted his COVID-19 policymaking (Bland, 2 February 2021). For anyone with elementary knowledge of WHO and CDC protocols on pandemics Soderberg's admittedly astute saga would act much better as anything more than a reminder of basic security rules in pandemics. Hancock's shielding regime was not actually following Soderberg's movie arc but using it to examine the rules in a proposed fictional sequence of actions. Likewise, the film's end, which proposes that the fictional virus migrated with displaced bats to pig-farming areas when their natural habitats were destroyed through deforestation may be an astute reference to scientific hypotheses concerning ecological entanglements, but it is not of Soderberg's inception. Similar theses circulate in science circles with reference to a relatively recent outbreak of Anthrax in the Arctic. The outbreak was linked to infected carcasses or spores released from the active layer over permafrost. The re-emergent disease, which affected severely reindeer herds in Siberia and was spread to humans through farming, was blamed on uncontrolled thawing and thickening which in the context of climate change encouraged the spread of this pathogen in a region facing warming temperatures (Stella et al., 2020). I will elaborate on a similar hypothesis in the following part but provide a safety belt for it missing from Soderberg's speculative fiction, which aims to eliminate the movie's problematic ambiguity. My worry is the normative arc of this link, which produces reality in the face 
of uncertainty. This is even more problematic in cinematic aetiologies which are based on successions of images. Straightforward causal links of this type are absent from real-world complexity - or they are rather difficult to subject to truth and reality tests. Excellent though Soderberg's artwork may be, it is not science, but an artfully crafted narrative that may inspire a scientifically educated policymaker.

Today, scholars working on sustainable futures recognise that science fiction narratives are useful tools in drafting long-term thinking about technology and science (Miller and Bennet, 2008; Milkoreit, 2017). Such long-term thinking is not an intermediate product of rational planning, but a journey commencing in the invisible regions of atmospheric phenomena, including those triggered by affective responses to horror and insecurity. At this stage, reason and planning are absent - as they are while watching a gripping movie. When this book appears to border on the incredible, it attempts to bridge the atmospheric with the realist in experimental styles, which have left behind this early phase of horror, allowing space for organised sensibility: social scientific argumentation. Experiments with the unknown and the unpredictable can generate vocabularies of action: a grammar of complexity taking on board physiological/biological inheritances and their cultural rhizomes (Derrida, 1976; Barad, 2007, 2010; Tzanelli, 2020a). One of the leading proponents of post-colonial magical realism, Alejo Carpentier, complained that his travels to China had left him with a feeling of incomplete knowledge about this civilisation's cultural complexity. Understanding involves knowing the language - a process, which, for Carpentier ([1947] 1995, p.77) involves learning the meaning of embodied performance in Chinese theatre. I will be returning to a meta-reflexive analysis of this experiment in the conclusion, where I assess the role of the performative in today's Theatrum Mundi (Tzanelli, 2013, Chapter 1). The Virocene is an unpleasant biomedical occurrence as much as it is the outcome of a meta-crisis that humanity experiences today: that of representation and becoming (see also Slaughter, 2012). Unless we embrace the dystopic imaginary, we will not exit the darkness of the moment (Bloch, 1986). The actualisation of any utopia is not just in the method used to transcend the gloom (e.g., Levitas, 2013a), but the lived experience of darkness (Rich, 2001).

\section{THE STRUCTURE OF THE BOOK}

We are in the domain of critical social inquiry - in particular, a contact zone between 'crisis', 'criticality', mobilities and scientific futurology. Krísis,

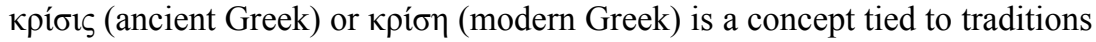
of European social thought. It is often associated with ancient Greek philosopher Aristotle's thesis on critical thought, which was revised by Enlightenment philosophe Immanuel Kant. To critique is, above all, to exercise rational 
judgement to determine how to navigate our external environments - that is, live, act on/within them and flourish as social beings. Critical thought is also associated with three generations of Frankfurt School social theorists, who interrogated the pitfalls of industrial modernity, an excessive rationalisation of social action and the subsequent loss of social autonomy and personal freedom. If one works from a combination of science and technology studies (STS), classical critical and new mobilities theory, as I do, they need to clarify the epistemological formations of crisis in relation to the current global pandemic. I plotted this study across discussions of atmospheric inter-mediations of the crisis that cover the following:

1. Techno-crisis: how does the COVID-19 pandemic and any pandemic affect our control over ways of knowing about, reflecting upon, and managing our social, physical, and cultural environments?

2. Praxeological crisis: what sort of physical, cognitive, emotional, social, economic, and political limitations does a global pandemic introduce in our lives? What are the consequences of this shrinking of horizons of action and expectation?

3. Emancipatory crisis and new utopias: what kind of new avenues of action can a pandemic open for human and environmental flourishing? Do we witness the emergence of alternative discourses and narratives of individual and collective (un)freedom in the current context?

4. Have we been myopic and Eurocentric in our understandings of 'crisis', both in terms of the analytical traditions that we use to analyse it and the contextual significance and challenges posited by a biological/biomedical menace?

5. Crisis as futural judgement: how can we envisage the 'after' or 'post' pandemic in practical and creative terms?

This seems like an impossible project if priority is given to these particular inter-mediations instead of their journey (or processual entwining). I prioritise the journey and its direction to particular spatio-temporal nodes, which will transform the cacophony of such plurality to a symphony. Otherwise put, all the aforementioned epistemological articulations of the crisis are explored in specific contexts of atmospheric (im)mobility to consider meeting points and commonalities that do not exclude experience, but set it on a par with reflexivity, materiality and mobility. The documenting mode of the crisis is distributed in atmospheric mediations between politics, society and culture and across two different domains: that of clearly articulated intentionality centring on institutionalised power and control, and the anarchic domains of revolt, play and leisure. The two domains do not exist as watertight compartments: in the form of either ludic performance or political gaming, and regardless of its mul- 
tiple context-bound cultural articulations, 'play' is a quintessential formation of vitalism partaking in human and post-human becomings (Huizinga, 1949] 2016). Play feeds and is fed by imagination and articulates different imaginary tropes.

Part II introduces the notion of the 'Virocene' and positions it analytically in realist accounts of crisis. It also discusses the broader parameters of perception and how these informed practices of governance: the management and mismanagement of the virus. Korstanje (2021, pp.199-202) goes into great depth in providing an excellent genealogy of the 'crisis' with reference to disaster management and its function in cultures of containment and communal sustainability. However, I endeavour to argue that this analysis is part of a far greater web of discursive possibilities and potentialities, which exemplify the contradictory depth of the cultural politics of emotions. The organisation of polities on principles that borrow from ideas of 'security', 'siege', 'friction', and 'containment', reinforcing cultures of exclusivity in the political domain certainly constitutes a reality. However, in some instances, the terror of human elimination has also opened the 'community' to the world, making people appreciate mobility more. Here, the New Hyperobjective supports Virocenic scenarios of immobility that modulate traditional conceptions of geographic border-ness as well as cultures of flexible citizenship (Richardson, 2013). Virocenic scenarios are based on the accumulation of events to form a global archive of changes in mobility. Even if the pandemic is addressed effectively with the discovery and global administration of an effective vaccine (something that will encounter obstacles of scientific, technological, ideological, and economic nature - see conclusion), this archive will remain and develop into a potent interpretative pole for future generations. In fact, such interpretative repertoires will also affect narratologically and pragmatically creative imaginaries, including those of film and tourism.

In Chapters 1 and 2 I provide the analytical parameters of mobilities in socio-political terms, by maintaining a planetary and multi-polar perspective on the COVID-19 crisis. I begin by hypothesising a recurring overlap of the 'Anthropocene' with the 'Virocene'. The Anthropocene is posited as a geological age or period commencing with either automobile invention or the Industrial Revolution, during which human activity has been the dominant influence on climate and the environment. Contrariwise with this historically incremental, if at times discontinuous or non-linear, imaginary, the Virocene involves the episodic governing of human fortunes, side-lining again environmental concerns - an observation I extend in Part IV, where I am talking about tourism and technological mobilities. Rather than thinking of the 'Virocene' as a self-contained period, we should consider it as an unpredictable rhizomatic phenomenon. Exposing the limitations of technology and science, the global onset of COVID-19 as a catastrophic évènement suggested that Virocenic 
discharges enmesh and corrupt autonomous imaginaries of mobility (travel, social connectivity, and global political solidarity). The human body seems to have been consumed at both physical and metaphorical levels: by a virus and thus a physical disease, but also due to its displacement to representational sites, in which time becomes a 'heritage repository' to exploit. Karen Barad (2007, 2010) discusses the ways inheritance and indebtedness partake in the production of spatio-temporal configurations of agency: phenomena such as the current pandemic stretch across time to produce archives that transcend the mode of particular autobiographical stories. This is how I conceptualise the iotic nature of the Virocene. I focus on four distinctive ways to reconsider the significance of agential potentiality in such epochal transformations: (a) thinking in terms of clusters of 'events' or 'episodes' of civilisational development or decline, not 'ages' (la longue durée); (b) tracking the ends of Virocenic rhizomes, as these enable the uncontrolled growth of risks across and within borders; (c) focusing on cultures of control, rather than surveillance, to manage biomedical phenomena in democratic ways; and (d) being mindful of harmful reactivations of behaviours belonging to the global bureaucratic and colonial archives.

In Part III I revisit traditional analytical bifurcations between work and leisure during lockdowns. In Chapter 3 I examine the effects of working from home policies and their impact on social life and the work ethic. I examine the acceleration of the invasion of the public into the private sphere, by reinterpreting Ardentian understandings of unprecedentedness, as these featured in recent explorations of the 'new spirit of capitalism', 'surveillance capitalism', and the 'Capitalocene'. All three theses invite sociological and geographical evaluations of organisational cultures of speed in social and digital terms. Such evaluation brings into sharp focus the shattering of temporal privacy and the domination of a particular form of digital surveillance, with various psychological, social, and political consequences for workers. In tandem, however, I will be exploring status and social differentiations of work, by considering the degrees of safety and shielding that apply to different professions. The overall argument will prompt social scientists to rethink the moral and socio-political basis on which precarity is defined in nodal contexts of mobility, hypermobility, and immobility of labour during COVID-19.

In Chapter 4 I proceed to assess the impact of the latest Virocenic episode on micro-social interactions and the foundations of a healthy relationship between the human subject and the world - what can be discussed in Archer's (2003) terms as the 'internal conversation'. Taking as a starting point the notion of 'micro-spheres of experience', the chapter analyses and considers the consequences of mobility constrictions. Such restrictions challenge the ideas that 'small is (necessarily) beautiful' and 'grand is incomprehensible' alike to examine instead socialising interactions during lockdowns and changes 
in leisure patterns in more dispassionate terms. Overall, the chapter defines anew connections between leisure, micro-travel or local/neighbourhood peregrinations, hobby activity and systemic tourism movements as interconnected forms of 'documentary' sense-making, rather than 'objective' perceptions of the environment (Mannheim, 1952). A Virocenic perspective on these activities, which can be more individually regulated than systemic tourism mobilities, suggests resistance to new hyperobjective calls for conformity in leisure micro-mobilities. At the same time, we must be mindful of questions of social and cultural access to such newly discovered leisure activities. The latter suggests an evaluation of the poetics and the politics of leisure regarding cultural codes and human 'tokening' - two major poles of social analysis on gender, sexuality, class, disability, and race. In such contexts, we find a reassertion of the body not just as material but also an emotional site conducive to atmospheric production and consumption.

Part IV returns to macro-social and global domains of consumption to assess the validity of scripts of hope and recovery. COVID-19 has exposed the limits of our capacity to efficiently address threats to both human and environmental ecosystems. As once popular tourist locales/destinations are turned by COVID-19's spread into risk zones with morbid biographical records, their identities altered, and their imaginaries of suffering become anthropocentric. The latest Virocenic episode has affected the management of recreational systems of mobility: from urban infrastructures to large representational centres and their figurative scapes and flows, to styles of leisure and play, such as tourism, our wellbeing mobilities have changed. Chapter 5 examines the coexistence of different, antagonistic tourism imaginaries in global post-viral social landscapes. Such antagonisms may be resolved at the expense of the ethics of tourism mobility, if not adjudicated by a post-human reflexivity. Unreflexive Virocenic behaviours involve the refusal to conform to lifesaving 'stay-at-home' policies, the tendency to book holidays without personal risk assessment, and the public inspection of death zones. Each of the consumption styles explored in this chapter to discuss post-COVID-19 recovery corresponds to at least one tourist imaginary, antagonistically placed against social imaginaries of moral betterment, solidarity, scientific advancement, national security, and labour equality. Data in the public domain suggest a split between pessimistic and optimistic attitudes that forge different tourism futures. These attitudes inform different imaginaries with different temporal orientations and consumption styles.

The fifth chapter does not abandon the biopolitical framework within which the Virocene and the New Hyperobjectivity were developed but places both in global market domains. In these domains, both phenomena/concepts are often reduced to auratic products that tourists consume (dark tourism, ecotourism, agritourism, slow tourism and so forth). Employing Castoriadis' differentia- 
tion between social and radical imaginaries, Foucault's biopolitical analysis, Sorokin's work on mentalities and Sorel's reflections on violence, I argue that we have entered a new phase in the governance and experience of tourism, which subsumes the idealistic basis of tourist imaginaries as cosmopolitan representational frameworks under the techno-cultural imperatives of risk, individualistic growth through adventure ('edgework') and heritage preservation. At the same time, however, we need to reconsider the contribution of technology, rather than technocracy, to sustainable post-COVID-19 scenarios of tourism recovery. In fact, such recovery scenarios extend beyond conventional ideas of tourism, as their strong imagological dimension provides new opportunities for digital forms of movement through film and video games. The latter is the theme of Chapter 6. On the one hand, the stylistic production of constellations of falling stars (dys-asters) develops marketable industrial significations (in movies, TV series and computer game franchises), thus strengthening capitalist mobilities. On the other, it schematises scenarios of escape from the fall by merely producing coherent 'arrows' of iotic movement in the Virocene.

The conclusion will critically consider the production of new forms of movement and new moral codings of immobility. A constant discursive thread in dystopian Virocenic landscapes has been the fear of a pattern of $d y s$-astrous immobility. This immobility will be progressive and conform to linear patterns of vertical velocity. Such dystopian public and political discourses recycle biblical forms of fall. The crypto-conservative artistic storyline commences with the elimination of large systems of long-haul travel but develops (while 'descending') to the reduction or elimination of the micro- and meso-mobilities of walking, driving, or commuting. This grand narrative of dark Virocenic futures appeals to human conservatism shared across political camps, and feeds into dark leisure markets. Another discursive thread exaggerates the efficacy of policymaking on bright futures, by flagging ecologically friendly mobilities as a solution to tourism recovery specifically. A similar argument is put forward for the management of privileged business migrations and climate change-induced population movements.

As I already stated, the problem with such optimism is that does not always evaluate complexity: the onus of structural sustainability is that it is always asked to sustain environments, labour, and business at the same time. Often, the result is the gross exploitation of environments and communities suffering from immobility so that the rest of the world continues to move towards a self-induced chaos. In the second scenario, the Virocenic landscapes recede in a metaphorical background as constellations of inequalities. Contrariwise, the New Hyperobjective is promoted to an all-encompassing version of recurring crises, which affects multiple ecosystems, often because of the thoughtless machinations of its optimistic policymakers and opportunistic entrepreneurs. 
When poorly considered scenarios of recovery prove that sustainability does not work, the New Hyperobjective regresses to a destructive atmosphere of revolt, akin to the social movements that brought about the collapse of the Weimar Republic. This was the period in which the New Objectivity appeared as an artistic protest against escapism, inaction, and political corruption (Hemingway, 2017). This ideological regression is experienced today at a discursive level as the effect of the governance of mobilities and not of particular social institutions. Indeed, atmospheric regressions of this kind translate viral immobilities to a Virocenic mega-ecology that promotes hatred and social upheaval. I predict without reservation that this will continue and mutate after the end of the current pandemic. Alternative ecological visions seemingly deprived of non-polemical content can be equally problematic when they invoke the image of the voyager, the pilgrim or even discoverer of cures to discuss hope as salvation. The voyager was the first coloniser of the weak and the first slayer of difference. Yet, equally judgementally, we jump centuries into the future to impose the same formula onto a totally different ideal type. As the story goes: beware of Virocenic pilgrims both of their opportunistic styles and their cosy insularity from the weight of the world. It is as if we have entered a mass, rather than the space of critical scholarship.

When the mass is over, many visit the opposite camp to see if the offer is better. As realists, we may hold that truth stems from the 'world' in which it is made. The Virocene's New Hyperobjective pushes humanity to opt either for a general factness that is then used to govern our present and our futures, or the cult of 'necessity' (Keller, 2007). It is as if we are condemned to enact a philosophical battle between Spinoza and Leibniz, in the hope that we will retrieve the 'truth' and manage to fix everything. Ultimately, this book asks what happens if to resolve Virocenic dilemmas of (im)mobility we first consider the ontological properties of the things that move to re-evaluate the honesty with which these truths are made (Armstrong, 2004, p.67). 'Honesty' here prioritises an investigation into the discursive properties of realist mediatisations, through which viral realities are produced as (hyperobjective) totalities. Such productions feed into our understanding of how we should be, behave and progress as a species, and especially how we should build inclusive or exclusive worlds: societies free of divisions, inequalities, rivalries, and hierarchies based on allegedly factual qualities. Thus, invoking 'Altermodernity' as an analytical framework should not be confused with Dussel's (1985) foundationalist thesis, or an unmodified perspective on holism we find in Wilber's (1996) work. The problem with both theses, but especially Dussel's, is that a return to the Catholic metaphysics of suffering is in reality anything but conducive to inclusivity. Solutions should first acknowledge the messy realities of human nature and thus accept technological innovation as a destructive-creative property in them. For this reason, the Conclusion scrutinises New Objectivity 
from the perspective of what Eve Chiapello (2004) saw in the romantic/New Age 'artist critique' of modernity. Although I will provide glimpses of the problems brewed by reactions to Virocenic discharges - both from below and from above - no thesis that draws on constructivism and merology should be presented as a stable ideological vision of the world. Solutions often come from the source of the problem, and in our case, this involves revisiting the epistemological basis from which we examine the ontological problems of the Virocene. 